\section{NU UNA Kastamonu Eğitim Dergisi Kastamonu Education Journal}

Eylül 2019 Cilt:27 Sayı:5

kefdergi.kastamonu.edu.tr
Başvuru Tarihi/Received: 09.11.2018

Kabul Tarihi/Accepted: 02.01.2019

DOI: $10.24106 /$ kefdergi.3423

\title{
Yazma Öz-Yeterlik Ölçeğinin Türkçeye Uyarlanması
}

\section{Turkish Adaptation Of Writing Self-Efficacy Scale}

\section{Öz}

\author{
Meryem YILMAZ SOYLU', Buket AKKOYUNLU²
}

Bu çalışmanın amacı Bruning ve arkadaşları (2013) tarafindan geliştirilen Yazma Öz-yeterliği Ölçeğinin Türkçeye uyarlanarak yazma öz-yeterliğini ölçmede psiko-metrik olarak geçerli ve güvenilir bir araç olup olmadığını değerlendirmektir. Aktarma, fikir üretme ve öz-düzenleme alt ölçeklerine sahip orijinal ölçek 16 maddeden oluşmaktadır. Dil geçerliği için alandaki uzmanlar ve ölçeği geliştiren grupla çalışılmıştı. Ölçeğin Türkçe formu 648 ortaokul öğrencisine uygulanmıştr. Yapı geçerliği için doğrulayıcı faktör analizi kullanılmıştr. Analizler sonucunda, uyarlanan ölçeğin 13 maddeden ve orijinal ölçekteki gibi üç boyuttan oluştuğu sonucuna ulaşılmıştr. Alt ölçeklere ait iç tutarlık (Cronbach Alfa) katsayıları hesaplanmıştı. Aktarma boyutunda iç tutarlığın .82, fikir üretme alt boyutunda .87 ve öz-düzenleme boyutunda da .84 olduğu bulunmuştur. Analiz sonuçları, Türkçeye uyarlanan Yazma Öz-yeterliği Ölçeğinin yazma öz-yeterliğini ölçmede dil eşdeğerliği olan geçerli ve güvenilir bir araç olduğunu göstermektedir.

Anahtar Kelimeler: öz yeterlik, yazma öz-yeterliği, yazma, aktarma, fikir üretme, öz-düzenleme, ölçek uyarlama

\section{Abstract}

The purpose of this study was to adapt Self-Efficacy of Writing Scale (Bruning et. al, 2013) to Turkish and to examine its psychometric reliability and validity. The original scale consisted of 16 items and has three sub-scales naming convention, ideation and self-regulation. The authors worked with Turkish experts and the authors of the original scale to assess linguistic validity of translated scale. Six hundred forty-eight middle school students filled the Turkish version of the scale. Confirmatory factor analysis was used to examine construct validity. Analyses showed that adapted scale has 3 sub-scales including 13 items total. For internal reliability of each sub-scales, Cronbach Alpha coefficient were calculated. Cronbach Alpha coefficient for convention sub-scale was .82 , this coefficient was .87 and .84 for ideation and self-regulation sub-scales respectively. Overall, analyses showed that Turkish version of Self-Efficacy of Writing Scale was linguistically and psychometrically valid and reliable to measure writing self-efficacy.

Keywords: self-efficacy, writing self-efficacy, writing, convention, ideation, self-regulation, scale adaptation 


\section{Extended Abstract}

Introduction: Many researchers have been working on developing scales for measuring writing self-efficacy because of its crucial role in writing and other academic fields (Bruning et. al, 2013; McCarthy et. al, 1985; Pajares, 2007; Pajares \& Johnson, 1996; Pajares \& Valiante, 1999; Shell et. al, 1989; Zimmerman \& Bandura, 1994; Zimmerman \& Kitsantas, 2007). Among these researchers Bruning et. al (2013) developed a Self-Efficacy of Writing Scale based on psychological and linguistic aspects of writing as well as cognitive models of this multidimensional process. The aim of this study was to adapt Self-Efficacy of Writing Scale (Bruning et. al, 2013) to Turkish and examine reliability and validity of this adapted scale.

Method: The Self-Efficacy of Writing Scale (SEWS) (Bruning et. al, 2013) has three dimensions including 16 items in total. Convention subscale consisted of five items aiming to measure self-efficacy of expressing ideas in writing. Ideation subscale also contained five items to measure self-efficacy of generating ideas for writing. Self-regulation of writing self-efficacy subscale included items for assessing confidence in managing different dimensions and sub-tasks of writing process. As suggested by Pajares, Hartley and Valiante (2001) 0-100 response type was used for each item. The more the total scores increased, the more the students considered efficacious in writing.

Turkish experts and the authors of the original scale assisted translation and back-translation of the scale in order to create linguistically valid measurement. Six hundred forty-eight middle school students filled the Turkish version of the scale. Gender distribution of the participants was almost equal. Of those reporting gender $(n=646)$, $316(49 \%)$ were girls and 330 (51\%) were boys. Grade level distribution of the participants showed that number of seventh and sixth grade students was equal $(n=177)$. One hundred fifty-six students reported themselves fifth graders and 136 students were eighth graders.

Results: After performing the initial analyses for normality and missing data, Kaiser-Meyer-Olkin (KMO) and Bartlett's Sphericity test were conducted to see if data set was appropriate for factor analyses. KMO Sampling Adequacy Value was 0.937 and Bartlett's Sphericity Test was statistically significant $(p<0.000)$, indicating that factor analysis could be run on the data.

Since Bruning et. al (2013) developed writing self-efficacy scale in three-factor structure and their analyses supported this solution, we used confirmatory factor analysis (CFA) to test if our dataset reflected the same structure. We first sought to determine goodness of fit of the SEWS data to a three-factor model as proposed in the original study (Bruning et. al, 2013). The fit was unacceptable (c2 (101) $=361.322, p<.000$, RMSEA=0.089, SRMR=0.059, $\mathrm{CFI}=0.895, \mathrm{TLI}=0.875)$. Then we checked the factor loadings and other parameters to understand why model was not fitting. As factor loading of item 16 was relatively low, we dropped this item and re-analyzed the data with CFA. However, the fit was not as good as it should be $(c 2(87)=347.870, p<.000$, RMSEA $=0.096$, SRMR $=0.061, C F I=$ $0.895, \mathrm{TLI}=0.875$ ). Output parameters were then examined and item 5 was dropped because it had almost equal loadings in first and second factors. The fit indices were better $(c 2(74)=204.122, p<.000$, RMSEA $=0.074$, SRMR= $0.047, \mathrm{CFI}=0.942, \mathrm{TLI}=0.929$ ) but still not satisfying. The model modified by dropping item 10 because of low factor loading in second dimension and high correlations with items in other factors. The fit was good (c2 $(62)=137.108$, $p<.000, \mathrm{RMSEA}=0.061, \mathrm{SRMR}=0.038, \mathrm{CFI}=0.964, \mathrm{TLI}=0.955)$ indicating that this model adequately explained the data's structure, so no further models were tested. The fitted data, which encompassed 13 items, was consistent with the three-factor structure. Cronbach Alpha coefficients were calculated to determine reliabilities of three sub-scale. Results were high. Cronbach Alpha for the four items related to the convention sub-scale was 0.82 , for the four ideations items 0.87 , and for the five self-regulation items 0.84 .

Discussion and Conclusion: The results of the study showed that Turkish version of Self-Efficacy of Writing Scale, consisted of three-subscale, was a valid and reliable measure for assessing self-efficacy of writing in Turkish language. 


\section{Giriş}

Günümüzde hem gündelik yaşam hem de iş yaşamı elli yıl öncesine oranla daha zor ve karmaşık görünmektedir. Kişisel ve profesyonel yaşamda başarılı olabilecek kişilerin sahip olması gereken özellikleri belirleme üzerinde çalışan araştrmacılar iş-birliği, iletişim, eleştirel düşünme ve yaratıılık becerilerini 21. yüzyılda sahip olunması gereken özellikler arasında sıralamışlardır (Conley, 2007; Levy \& Murnane, 2004; McLoughlin \& Lee, 2008; Redecker \& Punie, 2013; Scott, 2015; Sternberg \& Subotnik, 2006; Wagner, 2010). Bu dört önemli becerinin okuma ve yazma becerileri ile ilişkili olduğu birçok çalışma ile ortaya konulmaktadır (Amabile, 1996; Beghetto, 2005; Cropley, 1992, 1997; Faris, Golen, \& Lynch, 1999; Gardner, 1988; Krapels \& Davis, 2003; McVey, 2008; Russ, 2009; Sak, 2004; Scanlon, 2006; Smith, Paradice \& Smith, 2000; Sturgell, 2008; Torrance, 1992). Bilginin toplanması, rafine edilmesi, genişletilmesi, saklanması ve aktarılmasında kritik rol oynayan yazma becerisini geliştiremeyen öğrencilerin eğitimin üst basamaklarına ulaşmada ve potansiyellerini gerçekleştirmede güçlük çekeceği bilinmektedir. İş yaşamındaki yetişkinlerden de üst düzey yazma becerilerine sahip olmaları beklenmektedir. Yazma sürecinde sorun yaşayan, yazma performansı düşük olan yetişkinlerin daha iyi bir kariyere ulaşma konusunda sıkınt yaşayacakları çeşitli çalışmalarda belirtilmiştir (Harris, Graham, Brindle \& Sandmel, 2009; Graham 2008; National Commission on Writing, 2004, 2005).

Temel beceriler arasında yer alan yazma becerisi, yazmadaki düşünceler ve mesajlarla iletişim kurma, bilgiyi doğru ve tam olarak kaydetme; mektuplar, yönergeler, el kitabı, raporlar, öneriler ve grafikleri bir araya getirerek yaratıcı ya da özgün dokümanlar oluşturma olarak tanımlanmıştır (Herrington, Hodgson \& Moran, 2009; SCANS, 1999). Yazma, duyduklarımızı, düşündüklerimizi, tasarladıklarımızı, görüp yaşadıklarımızı yazı ile anlatmak; başkaları ile iletişim kurmanın, kendimizi anlatmanın bir yoludur (Sever, 2004). Özbay’a (2011) göre; ise yazma, duygu, düşünce, istek ve olayların belli kurallara uygun olarak birtakım sembollerle anlatımasıdır. Özellikle sayısal çağda Web 2.0 araçlarıyla birlikte yazma daha da önem kazanmış, bunların etkisiyle yazma eyleminin biçimi değişmiştir. Başka bir deyişle, teknoloji, yazma eyleminin amacı, süreci ve biçimini değiştirmiştir.

Yazma performansını etkileyen değişkenler incelendiğinde, öz-yeterliğin yazma performansı, yazma stratejilerinin kullanımı ve yazma yeterliklerini en iyi yordayan değişken olduğu görülmektedir (Martinez, Kock, \& Cass, 2011; Matoti \& Shumba, 2011; Pajares, 2007; Bandura, 1997; Hidi \& Boscolo, 2008; Pajares, 2003).

Bir alanda başarılı performans sergileyebileceğimize dair öz-güvenimizi gösteren öz-yeterlik inancı, o alandaki bir işi yapmaya olan isteğimiz ve o işi yaparken karşılaştğımız zorlukları aşma gücümüzle çok yakından ilişkilidir (Bandura, 1997, 2006). Bandura' nın (1997) kişisel irade/eylemlilik mekanizmalarındaki bileşenlerin en kapsamlı ve önemlisi olarak tanımladığı öz-yeterlik, bir alandaki bilgi ve beceri birikiminden görece daha önemli sayılmıştır. Sahip olunan bilgi ve beceriler ne kadar iyi olursa olsun, eğer bir kişi sahip olduğu bilgi ve beceri ile ortaya koyduğu eylemleri sonucunda istenen etkiyi (bir hedefe ulaşma, bir işi tamamlama vb.) yaratabileceğine inanmıyorsa, harekete geçmeyecek ya da bu konuda gönülsüz olacaktır.

Yazma ve yazma ile ilişkili diğer alanlarda kritik bir yere sahip olan yazma öz-yeterliğinin ölçülmesi için birçok ölçek geliştirilmiştir ve bunlardan bazıları dilimize uyarlanmıştır (Güneş, Kuşdemir \& Bulut, 2017; McCarthy \& diğerleri, 1985; Şengül, 2013; Pajares, 2007; Pajares \& Johnson, 1996; Pajares \& Valiante, 1999; Shell \& diğerleri, 1989; Zimmerman \& Bandura, 1994; Zimmerman \& Kitsantas, 2007). Shell ve arkadaşları (1989) tarafindan geliştirilen "Okuma-Yazma Öz-yeterlik Ölçeği"nin 8 maddesi temel alınarak Pajares, Hartley \& Valiante (2001) tarafindan geliştirilen Yazma Öz-yeterlik Ölçeği (YÖYÖ), Demir (2014) tarafindan Türkçe'ye uyarlanmıştır. Bu ölçek geliştirilirken yazma, tek boyutlu bir yapı olarak ele alınmış ancak yapılan analizler basit (heceleme, zaman vb. ekleri kullanma) ve karmaşık (paragraf oluşturma, konu cümleri yazma vb.) yazma becerilerine ait öz-yeterliğe işaret etmiştir. Ancak yazmaya ilişkin bilişsel modeller (Bereiter \& Scardamalia, 1987, Flower \& Hayes, 1984, Hayes, 2006) çerçevesinde YÖYÖ boyutları ve maddeleri incelendiğinde ortaya çıkan bileşenlerin yazma sürecinin tümünü kapsamadığı görülmektedir. Bu durum, YÖYÖ’nin kapsam geçerliği açısından soru işaretlerine neden olmaktadır. Şengül (2013) ortaokul öğrencilerinin yazma öz-yeterliğini ölçmek için bir araç geliştirmiştir. Bu ölçek, yazma becerileri farkındalığı, yazma psikolojisi, kişisel ve genel ilerleme olmak üzere dört boyutta dağılan 40 maddeden oluşmaktadır. Geliştirilen bu ölçekte de yazmanın bilişsel modellerinde sözü edilen içerik oluşturma, bilgi aktarma, hedef belirleme gibi süreçlerin dikkate alınmadığı belirlenmiştir. Güneş, Kuşdemir \& Bulut (2017) tarafindan ilkokul öğrencilerinin yazma öz-yeterliğinin ölçülmesi için geliştirilen Yazma Öz-Yeterlik Ölçeği'nin yazmada yetkinlik, planlı yazma, bağımsız yazma boyutlarından oluşan 10 maddelik bir ölçme aracı olduğu görülmüştür. Bruning ve arkadaşları (2013) yazmaya ilişkin modeller çerçevesinde yazma sürecindeki psikolojik ve dilsel yapıları da dikkate alarak, yazma öz yeterliği kavramını çok boyutlu ve bütüncül bir yaklaşımla ele almıştır. Bu çerçevede geliştirdikleri Yazma Öz-yeterlik Ölçeği'ni aktarma, fikir üretme, öz-düzenleme boyutlarındaki maddeler ile daha kapsamlı bir şekilde ölçmeye çalışmışlardır. Bu çalışmada, yazma öz-yeterliğinin daha kapsamlı, geçerli ve güvenilir bir araçla ölçülebilmesi için Yazma Öz-yeterlik Ölçeği'nin (Bruning \& diğerleri, 2013) dilimize kazandırılması amaçlanmıştr. 


\section{Yöntem}

\section{Araştırma Grubu}

Çalışma grubu elverişli örnekleme yöntemi ile belirlenmiştir. Ankara ilinde bulunan bir özel okulda okuyan 648 ortaokul öğrencisi çalışmaya katılmıştı. Tüm maddelere cevap vermediği tespit edilen iki katlımcıya ait veriler analizlerden çıkartılmıştır. Katılımcılardan sınıf ve cinsiyet bilgisini dolduran öğrencilerin sınıf ve cinsiyete göre dağııımları Tablo 1'de verilmiştir.

Tablo 1. Çalışma grubunun sınıf düzeyi ve cinsiyete göre dağııımı

\begin{tabular}{lccc}
\hline \multicolumn{4}{c}{ Cinsiyet (N) } \\
\hline Sınıf düzeyi (N) & Kız & Erkek & Toplam \\
\hline 5. sınıf & 78 & 78 & 156 \\
6. sınıf & 86 & 91 & 177 \\
7. sınıf & 90 & 87 & 177 \\
8. sınıf & 62 & 74 & 136 \\
\hline Toplam & 316 & 330 & 646 \\
\hline
\end{tabular}

Tablo 1'de görülebileceği gibi katlımcıların cinsiyete göre dağılımı neredeyse eşittir. Çalışma grubunda 316 (\%49) kız öğrenci bulunurken erkeklerin sayısı 330 (\%51) dur. Sınıflara göre dağılıma bakıldığında 7. sınıf ( $n=177)$ ve 6. sınıf öğrencileri $(n=177)$ ilk sırada gelirken bunu, 5. sınıf $(n=156)$ ve 8. sınıf $(n=136)$ öğrencileri izlemektedir. Çalışma grubunun yaş ortalaması 11.7 dir. Katılımcıların çoğunluğunu 12 yaşındaki öğrenciler ( $n=185)$ oluştururken, bunu 11 ( $n=147), 13$ $(n=147)$ ve $10(n=124)$ yaşındaki öğrenciler izlemektedir.

\section{Ölçme Aracı}

Yazma öz-yeterliğine dair ölçeği geliştiren Bruning ve arkadaşları (2013) yazma sürecinde çalışan belleğin önemli rol üstlendiği modellerden (Bereiter \& Scardamalia, 1987, Flower \& Hayes, 1984, Hayes, 2006) yola çıkarak yazma eylemine ilişkin üç temel boyut tanımlamışlar ve Yazma Öz-Yeterliği Ölçeği'ni bu boyutlar çerçevesinde yapılandırmışlardır. Bu boyutlardan ilki aktarma (convention) olarak adlandırılan; yazılmak istenenlerin harf, yazım ve dilbilgisi kuralları yardımıyla yazılı forma dönüştürülmesini kapsayan yapıdır. Fikir üretme (ideation) boyutu olarak adlandırılan ikinci boyut ise semantik ve şematik bilgilere dayanarak yazı için fikir üretmeyi kapsamaktadır. Son boyut olan öz-düzenleme (self-regulation) boyutu, yazma etkinliğinin dışına kadar uzanmakta ve yönetme, izleme ve değerlendirmeyi içine almaktadır.

Her boyutta yazılan maddeler 0-100 arasındaki bir sayı ile ölçülmektedir. Öz-yeterlik ölçümünü psikometrik açıdan inceleyen Pajares, Hartley \& Valiante (2001) 0-100 biçimindeki ölçeklemenin likert biçime göre daha güçlü olduğunu belirtmektedir. Bu çerçevede, ölçeği doldururken katılımcılardan her madde için kendilerine duydukları güveni 0 (hiç) ile 100 (tam) arasındaki bir sayı ile değerlendirmeleri istenmektedir. Her alt ölçek toplam puanlar üzerinden analiz edilmekte ve öğrencilerin aldıkları puanlar arttkça kendilerine olan güvenlerinin arttğı kabul edilmektedir.

Ölçeğin boyutlarına ilişkin ayrıntılar aşağıda açıklanmıştır.

\section{Yazmada aktarma öz-yeterliği boyutu}

Fikirleri, yazılan dilde ifade etmeye ilişkin kuralların kullanımına dair öz-yeterliğin yoklandığı alt ölçek, aktarma öz-yeterliği olarak isimlendirilmektedir (Bruning \& diğerleri, 2013). İmla kurallarına göre kelimeleri sembollerle (harf vd.) ifade etme, noktalama işaretlerini kullanma, büyük/küçük harf kurallarına uyma ve cümle kurma becerileri bu boyutta değerlendirilmektedir. Yazma alanında uzmanlaşmış kişiler bu boyutta otomatikleşmiş davranışlar sergilerken henüz yazmayı yeni öğrenmiş kişiler için bu süreç daha çok dikkat ve çaba gerektirmektedir (Graham, 2006). Zaman kipleri, iyelik ekleri, hâl ekleri ve diğer dilbilgisi kurallarının uygulanması da aktarma boyutunda ele alınmaktadır. Bunlara ek olarak, tam cümle kurabilme, cümleleri birleştirebilme, kâğıt-kalem kullanarak ya da elektronik aygıtlar aracılığıyla yazabilme, gerektiğinde paragraf oluşturabilme, başlık yazabilme becerilerine ilişkin öz-yeterlik, aktarma boyutunda değerlendirilmektedir.

Bruning ve arkadaşlarının (2013) geliştirdiği ölçeğin aktarma öz-yeterliği boyutunda "Tam cümleler yazabilirim", "Kelimeleri doğru heceleyebilirim" gibi maddelerin yer aldığı beş madde bulunmaktadır. Bu boyuta ait güvenirlik değerlerine bakıldığında ortaokul örneklemi için Cronbach Alpha değerinin .85, lise örneklemi için Cronbach Alpha değerinin .86 olduğu görülmüştür. 


\section{Yazmada fikir üretme öz-yeterliği boyutu}

Yazma sürecinin başlaması ve devam etmesi, fikir üretme olmadan zor görünmektedir. Yazmaya ilişkin modeller incelendiğinde fikir üretmenin bu modellerin önemli bileşenlerinden biri olduğu görülmektedir (Flower \& Hayes, 1984; Flower \& Hayes, 1996; Hayes, 1996, 2006). Bu modellerde fikir üretme, çalışan bellekte devam edegelen ve yazma sürecinin bütün bileşenlerine etki eden bir boyut olarak karşımıza çıkmaktadır. "Yazmak için fikrim var mı?" "Bunlar iyi fikirler mi?" "Fikirlerimi ifade edebilecek kelimeler bulabilir miyim?" sorularına verilen cevaplar bu boyutta değerlendirilmektedir.

Fikir üretme, semantik (anlamsal) alanda konumlandırılmakta, yazarın içerik türetebilme ve düşüncelerini sıraya koyabilme becerilerini de kapsamaktadır. Geliştirilen bu ölçekte ise fikir üretme maddeleri; yazarın fikre sahip olup olmaması, bu fikirlerin kalitesi ve sırasına ilişkin ifadeleri içeren beş maddeden oluşmaktadır. Bu boyuta ait Cronbach Alpha güvenirlik kat sayısının ortaokul ve lise örneklemi için sırasıyla .90 ve .92 olduğu görülmektedir (Bruning \& diğerleri, 2013).

\section{Yazmada öz-düzenleme öz-yeterliği boyutu}

Yazmada öz-düzenleme öz-yeterliği, yazma sürecine ait farklı boyutları ve alt görevleri başarılı bir şekilde yönetebilmeye dönük güveni yansıtmaktadır (Zimmerman \& Bandura, 1994; Zimmerman \& Kitsantas, 2007). Fikir üretme ve aktarma yazmanın vazgeçilmez bileşenleri olsa da bütün süreç bunlardan ibaret değildir. Öz-düzenleme becerileri sadece etkili yazma stratejileri kullanıp, fikirler üretmek için değil, aynı zamanda bu süreçte hissedilen duygu ve kaygıları yönetebilmek için de gerekli görünmektedir (Bruning \& diğerleri, 2013). Zimmerman \& Bandura'nın (1994) açıkladığı yazmaya ilişkin öz-düzenleme, bir yazıya başlayıp bitirene kadar geçen süreci ve etkinlikleri kapsamaktadır. Bunlar arasında yazmaya ilişkin bir konu bulma, zorlanmadan yazmaya başlama, okurun dikkatini çekme, yazma biçimini farklı okuyucu kitlesine göre ayarlama, tekrar düzenleyerek cümleleri anlaşılır hale getirme, yazmaya ilişkin problemleri çözme, konu çekici olmasa da yazmaya motive olma, dilbilgisi hatalarını bulma ve düzeltme becerileri yer almaktadır (Bruning \& diğerleri, 2013). Bu karmaşık süreçle baş edebilmek için yazarlar birçok öz-düzenleme stratejisine intiyaç duymaktadır. Yazarlar, söz-dizimsel ve anlamsal bilgiyi koordine etmenin yanı sıra yazı türlerinin gereklilikleri ve dikkat dağıttcı etmenlerle başa çıkarak yazma sürecinin safhalarını kontrol etmeye (Hidi \& Boscolo, 2008) ve hedeflerine başarıyla ulaşıp ulaşmadıklarını değerlendirmeye intiyaç duymaktadır. Yazma Öz-Yeterlik Ölçeğinin bu boyutu sözü edilen becerilerin uygulanmasında yazarların kedine duyduğu güveni ölçmeyi hedefleyen alt maddeden oluşmaktadır. Bu maddelerden bazıları: "Yazma ödevlerime hızlıca başlayabilirim.", "Yazarken dikkatimin dağılmasını önleyebilirim."

Ölçeğin diğer iki alt boyutu gibi bu boyuta ait güvenirlik katsayıları da yüksek düzeydedir. Ortaokul örneklemi ile yapılan çalışmada Cronbach Alpha değeri .88; lise örneklemi ile. 87 olarak bulunmuştur.

Orijinal ölçeğin bütün alt boyutlarına ait güvenirlik katsayıları incelendiğinde Cronbach Alpha katsayılarının hem ortaokul hem lise örneklemi için oldukça yüksek olduğu görülmektedir. Bu doğrultuda, yazma öz-yeterliğini ölçmede Yazma Öz-Yeterliği Ölçeği'nin oldukça geçerli ve güvenilir bir araç olduğu söylenebilir.

\section{Ölçeğin Uyarlanması}

Ölçeğin yazarlarından alınan izinle başlayan uyarlama çalışması kapsamında bütün boyutlardaki maddeler doktorasını İngilizce eğitim veren bir üniversiteden alan bir konu alanı uzmanı tarafindan Türkçeye çevrilmiştir. Türkçeye çevrilen maddeler üç konu alanı uzmanı tarafindan incelenip onaylandıktan sonra elde edilen form tekrar İngilizceye çevrilerek ölçeği geliştiren araştırmacılarla paylaşılmıştır. Orijinal ölçek ile tekrar İngilizceye çevrilen Türkçe ölçek arasında bir farkın olmadığı Bruning ve arkadaşları (Bruning, 9 Ekim, 2017) tarafindan onaylanmıştı. On altı maddeden oluşan bu ölçeğin uyarlama çalışmasında kullanılmasına karar verilmiştir.

\section{Veri Toplama Süreci}

Yazma Öz-yeterlik Ölçeği, öğrencilerin yazmaya ilişkin inançlarını değerlendirebilmek amacıyla yazmaya ilişkin inançları ölçen bir grup ölçekle birlikte uygulanmıştr. Uygulama yapılmadan önce veri toplanacak okulun yöneticileri, Türkçe zümre başkanı ve öğretmenleri hem yazma öz-yeterlik ölçeği hem de diğer ölçekler ile ilgili bilgilendirilmiştir. Uyarlanan yazma öz-yeterliği ölçeğinin maddelerini inceleyen yönetici ve öğretmenler uygulamanın yapılmasına onay vermişlerdir. Ardından, yazmaya ilişkin ölçekler öğretmenlerin rehberliğinde uygulanmıştr. Yazma Öz-Yeterliği Ölçeğinin cevaplanması 10-15 dk. sürmüştür.

\section{Verilerin Analizi}

Ölçeğin Türkçe formunun geçerlik ve güvenirliğine dair analizler yapılmadan önce veri seti betimsel istatistikler ile incelenmiştir. 
Orijinal ölçek üç boyutlu kuramsal bir modelle açıklandığı ve analizler sonucunda bu yapıların geçerliği ve güvenirliğine ilişkin güçlü sonuçlara ulaşıldığı için ölçeğin Türkçe uyarlamasına ait veriler doğrulayıcı faktör analizi kullanılarak incelenmiştir. Doğrulayııı faktör analizi Mplus programı yardımıyla yapılmıştır. Bu analize geçilmeden önce veri sayısının faktör analizi için uygun olup olmadı̆̆ını görmek amacıyla Kaiser-Meyer-Olkin (KMO) örneklem uygunluğu ve Barlett küresellik testleri uygulanmıştır.

\section{Bulgular}

Doğrulayıcı faktör analizinden önce örneklem sayısının yeterli olup olmadığını incelemek için yapılan Kaiser-Meyer-Olkin (KMO) ve Barlett testlerine ait sonuçlar Tablo 2' de görülmektedir.

\section{Tablo 2. KMO ve Bartlett testi sonuçları}

\begin{tabular}{lcc}
\hline KMO örneklem uygunluğu testi & & .937 \\
Bartlett's küresellik testi & $\chi 2$ & 5352.085 \\
& sd & 120 \\
& p & .000 \\
\hline
\end{tabular}

KMO değeri 0 ile 1 arasında değişmektedir. Kaiser (1974) bu değerin 0.6'dan büyük olduğu durumlarda örneklem sayısının kabul edilebilir düzeyde olduğunu belirterek 1ile 0.8 arasındaki değerlerin örneklem miktarının oldukça yeterli olduğuna işaret ettiğini belirtmiştir. Tablo 2 incelendiğinde veri setine ait KMO değerinin 0.94 olduğu, buna dayanarak örneklem sayısının faktör analizi için oldukça yeterli kabul edilebileceği görülmektedir. Bartlett küresellik testinin istatistiksel olarak anlamlı çıkması maddelerin birbiri ile ilişkili oldukları ve faktör analizinin yapılabileceğine işaret etmektedir (Friel, 2017). Yapılan analiz sonucunda Bartlett küresellik testi istatistiksel olarak anlamlı ve KMO değeri yüksek olduğundan veri setinin faktör analizi ile incelenmesine geçilmiştir.

Ölçeğin üç boyutlu yapısı daha önceki çalışmalara dayandırıldı̆̆ı (Dempsey, Bruning, Kauffman, 2010) ve kuramsal çerçeveyle (Pajares, 2007; Shell \& diğerleri, 1995, 1989; Zimmerman \& Bandura, 1994) açıklandığı, orijinal ölçeğinde geçerlik ve güvenirliği güçlü kanıtlarla desteklendiği için; uyarlanan ölçeğe ait veriler doğrulayıcı faktör analizi (DFA) ile incelenmiştir (Aşkar \& Mazman, 2013). İlk aşamada veri setindeki 16 madde, ilgili boyutlarda tanımlanarak model test edilmiştir. Test edilen model Hu ve Bentler (1999) tarafindan önerilen uyum indeksleri çerçevesinde değerlendirilmiştir. Buna göre CFI (Comparative Fit Index) ve TLI (Tucker Lewis Index) değerinin 0.95 ve üzerinde olması çok iyi, 0.90 ve üzerinde olması ise kabul edilebilir bir uyuma işaret etmektedir (Bentler, 1990). RMSEA (Steiger's Root-Mean-Square Error Of Approximation) değerinin 0.05 ten düşük olması çok iyi, 0.10 ve alttnda olan değerler ise kabul edilebilir uyum derecesini göstermektedir. SRMR (Standardized Root-Mean-Square Residual) değerinin ise 0.05 ten küçük olması çok iyi, 0.08 den küçük olması ise kabul edilebilir olarak yorumlanmaktadır (Hu \& Bentler, 1999).

Uyum indeklerine ait yukarıda söz edilen sınır değerler dikkate alınarak yapılan analizlere ilişkin değerler Tablo 3'te sunulmaktadır.

Tablo 3. Doğrulayıcı faktör modellerine ait uyum indeksleri

\begin{tabular}{|c|c|c|c|c|c|c|}
\hline Doğrulayıcı Faktör Modeli & Açıklama & $\begin{array}{l}\text { Toplam madde } \\
\text { sayısı }\end{array}$ & RMSEA & SRMR & CFI & TLI \\
\hline Birinci Düzey & 16 maddelik ölçek & 16 & 0.089 & 0.059 & 0.895 & 0.875 \\
\hline İkinci Düzey & $\begin{array}{l}\text { 16. madde faktör yükü düşük olduğun- } \\
\text { dan analizden çıkartılmıştır. }\end{array}$ & 15 & 0.096 & 0.061 & 0.895 & 0.875 \\
\hline Üçüncü Düzey & $\begin{array}{l}\text { 5. maddenin yükü birinci ve ikinci boyut- } \\
\text { larda eşit olduğundan analizden çıkartıl- } \\
\text { mıştır. }\end{array}$ & 14 & 0.074 & 0.047 & 0.942 & 0.929 \\
\hline Dördüncü Düzey & $\begin{array}{l}\text { 10. madde düşük faktör yükü ve diğer bo- } \\
\text { yutlardaki maddelerle yüksek ilişki gös- } \\
\text { terdiğinden analizden çıkartılmıştır. }\end{array}$ & 13 & 0.061 & 0.038 & 0.964 & 0.955 \\
\hline
\end{tabular}

Ölçekteki bütün maddelerin ( $N=16)$ analiz edildiği birinci düzey modelin uyum indekslerinin $\left(\chi^{2}(101)=361.322\right.$, $p<.000, R M S E A=0.089, S R M R=0.059, C F I=0.895, T L I=0.875)$ istenen düzeyde olmadığı belirlenmiştir. Faktör yükleri incelendiğinde öz-düzenleme öz-yeterliği boyutunda yer alan 16. maddenin yükünün düşük olduğu belirlenerek DFA

| Kastamonu Eğitim Dergisi, 27(5), 2019| 
tekrarlanmış ancak yine istenen uyum değerlerine $\left(\chi^{2}(87)=347.870, p<.000, \mathrm{RMSEA}=0.096, \mathrm{SRMR}=0.061, \mathrm{CFI}=\right.$ $0.895, \mathrm{TLI}=0.875$ ) ulaşılamamıştŗ. Bir sonraki adımda birinci ve ikinci boyutlardaki yükü eşit olan 5 . madde analizden çıkartilmıştr. Uyum indeksleri $(\chi(74)=204.122, p<.000$, RMSEA $=0.074$, SRMR $=0.047, C F I=0.942, T L I=0.929)$ iyileşme gösterse de istenen düzeye ulaşmamıştr. Model düzeltme önerilerine bakıldığında ikinci boyutta yer alması öngörülen 10. madde, hem faktör yükünün düşük olması hem de diğer boyutlardaki maddelerle yüksek korelasyøn değerleri göstermesi nedeniyle modelden çıkarthlarak analiz tekrar yapılmıştr. Uyum indeksleri incelendiğinde $(\chi 2(62)=137.108$, $p<.000, R M S E A=0.061, S R M R=0.038, C F I=0.964, T L I=0.955)$ model uyum indekslerinin iyi düzeyde olduğu görülmüştür. Bu modele ilişkin parametreler Tablo 4'te verilmiştir.

Tablo 4. Üç boyutlu yazma öz-yeterliği ölçeği modeline ilişkin parametreler

\begin{tabular}{llll}
\hline Boyutlar ve maddeler & Faktör yükleri & Standart hata & Standartlaşmış değer \\
\hline Aktarma & & & \\
Madde 1 & 1.000 & 0.000 & 0.636 \\
Madde 2 & 1.571 & 0.147 & 0.744 \\
Madde 3 & 1.724 & 0.151 & 0.841 \\
Madde 4 & 1.361 & 0.134 & 0.678 \\
\hline Fikir üretme & & \\
\hline Madde 6 & 1.000 & 0.000 & 0.741 \\
Madde 7 & 1.082 & 0.083 & 0.819 \\
Madde 8 & 1.216 & 0.089 & 0.787 \\
Madde 9 & 1.128 & 0.091 & 0.718 \\
\hline Öz-düzenleme & & & \\
\hline Madde 11 & 1.000 & 0.000 & 0.707 \\
Madde 12 & 1.082 & 0.085 & 0.776 \\
Madde 13 & 1.125 & 0.090 & 0.762 \\
Madde 14 & 0.808 & 0.069 & 0.708 \\
Madde 15 & 0.991 & 0.080 & 0.745 \\
\hline
\end{tabular}

Yazma öz-yeterliği diğer boyutlarla ilişkili örtük bir değişken olarak analize eklenerek maddeler ve boyutların bu değişkenle ilişkisi incelenmiştir. Uyum indeksleri incelendiğinde bu modelin iyi düzeyde uyum gösterdiği belirlenmiştir. Kabul edilen modelde yazma öz-yeterliğinin alt boyutları (aktarma, fikir üretme, öz-düzenleme) ile yazma öz-yeterliği arasındaki faktör yükleri (lambda $x, \lambda x$ ), t değerleri, ölçüm hataları (delta, $\delta$ ) ve her üç boyutun yazma öz-yeterliğini açıklama oranları $\left(\mathrm{R}^{2}\right)$ Tablo $5^{\prime}$ te verilmiştir.

Tablo 5. Yazma öz-yeterliği ölçeği ikinci düzey doğrulayıcı faktör modeli değerleri

\begin{tabular}{llccccc}
\hline & Boyutlar & $\boldsymbol{\lambda}$ Katsayısı & $\begin{array}{c}\boldsymbol{\delta} \text { Katsayısı Hata } \\
\text { varyansı }\end{array}$ & t değeri & $\mathbf{p ~}^{\mathbf{2}}$ & $\mathbf{R}^{\mathbf{2}}$ \\
\hline Yazma Öz-Yeterliği & Aktarma & 0.801 & 0.034 & 23.271 & .000 & 0.642 \\
& Fikir üretme & 0.915 & 0.030 & 30.618 & .000 & 0.837 \\
& Öz-düzenleme & 0.876 & 0.031 & 28.674 & .000 & 0.768 \\
\hline
\end{tabular}

Tablo 5'te sunulan faktör yükleri ve t değerlerine bakıldığında en yüksek ilişkinin fikir üretme ve yazma öz-yeterliği arasında olduğu ve bütün alt boyutların yazma öz-yeterliği ile anlamlı $(p<0.05)$ ve pozitif bir ilişki içinde olduğu belirlenmiştir. Yazma öz-yeterliği tarafindan alt-boyutlarda açıklanan varyanslara bakıldığında (R2) sırasıyla fikir üretme (0.84), öz-düzenleme (0.77) ve aktarma (0.64) boyutlarında değişkenlik olduğu görülmüştür.

Yazma öz-yeterliği ölçeğinin güvenirliğini gösteren Cronbach $\alpha$ değeri .90 olarak bulunmuştur. Aktarma ( $\alpha=.82)$, fikir üretme ( $\alpha=.87)$ ve öz-düzenleme $(\alpha=.84)$ alt boyutları da yüksek güvenirlik değeri taşımaktadır.

\section{Sonuç}

Bu çalışmada, Bruning ve arkadaşlarının (2013) geliştirdiği Yazma Öz-Yeterliği Ölçeği'nin Türkçe'ye uyarlanarak psikometrik özelliklerinin incelenmesi amaçlanmıştr. Dil- eşdeğerliğini sağlamak için uzmanlar eşliğinde yapılan çeviriler ve orijinal ölçeği geliştiren yazarlar grubuyla yapılan ortak çalışmalarla Yazma Öz-Yeterliği Ölçeği'nin Türkçe formu hazırlanmıştir. 
Ölçeğin orijinali geliştirilirken ortaokul öğrencileri ile çalışılmıştr. Ölçeğin Türkçeye uyarlama sürecinde de ortaokul öğrencileri çalışma grubu olarak seçilmiştir. Elde edilen veriler, DFA kullanılarak analiz edilmiştir.

Yapılan bir dizi DFA analizi her boyuttan birer tane olmak üzere orijinal ölçekteki maddelerden üç tanesinin elenmesini gerektirmiştir. Elde edilen on üç maddelik ölçekle ilgili uyum değerleri incelenmiş ve uyarlanan ölçeğin orijinal ölçekte olduğu gibi aktarma, fikir üretme ve öz-düzenleme alt boyutlarına sahip olduğu görülmüştür. Daha sonra alt boyutların ve ölçeğin tamamına ilişkin güvenirlik değerlerine bakılmıştı. Ölçeğin bütününe ait Cronbach $\alpha$ değerinin .90 , aktarma alt boyutunda .82 , fikir üretme alt boyutunda .87 ve öz-düzenleme boyutunda da Cronbach $\alpha$ değerinin .84 olduğu belirlenmiştir. Türkçeye uyarlanan ölçeğin güvenirlik değerleri orijinal ölçekteki değerlere çok yakın bulunmuştur. Geçerlik ve güvenirlikle ilgili yapılan bütün çalışmalar dikkate alındığında Yazma Öz-Yeterlik Ölçeğinin Türkçe formunun geçerli ve güvenilir bir ölçme aracı olduğu sonucuna ulaşılmıştır.

Genel anlamda öz-yeterliği, bireyin iradesini kullanıp eyleme geçmesi ve zorluklarla mücadele etmesi açısından değerlendiren ve bunu, bireyin kendine güveninin ayrılmaz bir parçası olarak kabul eden Bandura (1997, 2006), yazma öz-yeterliği ile de ilgilenmiştir. Yazma öz-yeterliğinin yazma eğitimi dışındaki öğrenme alanları ile yakından ilişkili olduğunu belirtmiştir. Bilişsel gelişim ve işlerliğin yazma okur-yazarlığı ile üst düzeyde ilişkili olduğunu vurgulamıştr (Bandura, 1993). Öğretmenlerin, öğrencilerin ve hatta velilerin öğrencilerin kompozisyon becerileri ile ilgili algılarına odaklanmasını öneren Bandura (1993), bu sayede öğrenenlerin okuryazarlıktaki ustalıklarının algılanan yeterlik düzeyini olumlu etkileyeceğini belirtmiştir. Bu alanda yapılan çalışmalar, yazma öz-yeterliğinin yazma becerisini desteklediğini ve yazma kaygısını azalttğını göstermiştir (Martinez, Kock, \& Cass, 2011; Matoti \& Shumba, 2011; Pajares, 2007; Bandura, 1997; Hidi \& Boscolo, 2008; Pajares). Hidi \& Boscolo (2008) okul çağındaki çocuklar ve yetişkinlerle yürüttükleri çalışmada, yazma öz-yeterliğinin yazma becerileri ve yazmada strateji kullanımını en iyi ön gören değişken olduğunu belirterek, yazma öz-yeterliği ile yazma performansı arasındaki yüksek ilişkiye vurgu yapmışlardır.

Uyarlanan bu ölçek, yazma sürecini aktarma, fikir üretme ve öz-düzenleme boyutlarında ele alarak yazarların yazmaya ilişkin yeterliklerini gözlemlenebilir kategorilerde izleyebilme firsat vermektedir. Bu üç faktörlü yapı kuramsal ve pratik olarak anlamlı bir model oluşturmaktadır. Bu nedenle hem uygulamada hem kuramsal alanda çalışma yapan araştrmacıların kullanabileceği bir ölçek olarak kabul edilebilir. Yazma becerisinin gelişimsel olarak incelendiği, yazmada cinsiyet farklılıkları, yazmaya karşı tutumlar, yazma motivasyonu, dijital ortamda yazmaya ilişkin araştırmalarda bu ölçekten yararlanılabilir.

\section{Kaynakça}

Amabile, T. M. (1996). Creativity in context. Boulder, CO: Westview Press.

Aşkar, P., \& Mazman, S. G. (2013). Çevrimiçi Bilgi Arama Stratejileri Envanteri' nin Türkçeye uyarlama çalışması. Eğitim ve Bilim, 38(168), 168-182.

Bandura, A. (1993). Perceived self-efficacy in cognitive development and functioning. Educational Psychologist. 28, $117-148$.

Bandura, A. (1994). Self-efficacy. In V. S. Ramachaudran (Ed.), Encyclopedia of human behavior (Vol. 4, pp. 71-81). New York: Academic Press.

Bandura, A. (1997). Self-efficacy: The exercise of control. New York: Freeman.

Bandura, A. (2006). Guide for constructing self-efficacy scales. In F. Pajares \& T. Urdan (Eds.). Self-Efficacy Beliefs Of Adolescents. (Vol. 5., pp. 307-337). Greenwich, CT: Information Age Publishing.

Beghetto, R. A. (2005). Does assessment kill student creativity? The Educational Forum,69(2), 254-263. http://dx.doi. org/10.1080/00131720508984694

Bereiter, C., \& Scardamalia, M. (1987). The psychology of written composition. Mahwah, NJ: Erlbaum.

Bruning, R., Dempsey, M., Kauffman, D. F., McKim, C., \& Zumbrunn, S. (2013). Examining dimensions of self-efficacy for writing. Journal of Educational Psychology,105(1), 25.

Bruning, R. (2017, Ekim 9). Kişisel iletişim

Conley, D.T. (2007). Toward a more comprehensive conception of college readiness. Eugene, OR, Educational Policy Improvement Center.

Cropley, A. J. (1992). More ways than one: Fostering creativity in the classroom. Norwood, NJ: Ablex.

Cropley, A. J. (1997). Fostering creativity in the classroom. In M. A. Runco (Ed.), The creativity research handbook (pp. 83-114). Cresskill, NJ: Hampton Press.

Demir, T. (2014). Yazma öz yeterlik ölçeğinin türkçe formunun geçerlik ve güvenirlik çalışması,E-Kafkas Eğitim Araştırmaları Dergisi,1(2), 28-35. 
Dempsey, M., Bruning, R., \& Kauffman, D. (2010). An empirical test of a new model of self-efficacy for writing. Poster presented at the Annual Meeting of the American Educational Research Association, Denver, CO.

Faris, K. A., Golen, S. P., \& Lynch, D. H. (1999). Writing apprehension in beginning accounting majors. Business Communication Quarterly, 62(2), 9-22.

Flower, L., \& Hayes, J. R. (1984). The representation of meaning in writing. Written Communication, 1, 120 -160. doi:10.1177/ 0741088384001001006

Gardner, H. (1988). Creativity: An interdisciplinary perspective. Creative Research Journal,1, 8-26. http://dx.doi. org/10.1080/10400418809534284

Graham, S. (2006). Writing. In P. Alexander \& P. Winne (Eds.), Handbook of educational psychology (pp. 457-478). Mahwah, NJ: Erlbaum.

Graham, S. (2008). Effective writing instruction for all students. Retrieved from http:// doc. renlearn.com/KMNet/R004250923GJCF33.pdf

Güneş, F., Kuşdemir, Y. ve Bulut, P. (2017). Yazma Öz Yeterlik Ölçeğinin psikometrik özellikleri. The Journal of Academic Social Science Studies, 58, 101-114.

Harris, K.R., Graham, S., Brindle, M., \& Sandmel, K. (2009). Metacognition and children's writing. In D.J. Hacker, J. Dunlosky, \& A.C. Graesser (Eds.), Handbook of metacognition in education (pp. 131-153). New York, NY: Routledge.

Hayes, J. R. (1996). A new framework for understanding cognition and affect in writing. In C. M. Levy \& S. Ransdell (Eds.), The science of writing: Theories, methods, individual differences, and applications (pp. 1-27). Mahwah, NJ: Erlbaum.

Hayes, J. R. (2006). New directions in writing theory. In C. A. MacArthur, S. Graham, \& J. Fitzgerald (Eds.), Handbook of writing research (pp. 28-40). New York, NY: Guilford Press.

Herrington, A., Hodgson, K. \& Moran, C. (2009). Teaching the new writing: Technology, change, and assessment in the 21st-century classroom. Teachers College Press. Language \& Literacy Series ERIC Number: ED527588

Hidi, S., \& Boscolo, P. (2008). Motivation and writing. In C. A. MacArthur, S. Graham, \& J. FitzGerald (Eds.), Handbook of writing research (pp. 144-157). New York, NY: Guilford Press.

Hu, L., \& Bentler, P. M. (1999). Cutoff criteria for fit indexes in covariance structure analysis: Conventional criteria versus new alternatives. Structural Equation Modeling, 6, 1-55. doi:10.1080/10705519909540118

Kaiser, H. 1974. An index of factor simplicity. Psychometrika. 39, 31-36.

Krapels, R. H., \& Davis, B. D. (2003). Designation of "communication skills" in position listings. Business Communication Quarterly, 66(2), 90-96.

Levy, F. \& Murnane, R. 2004. The new division of labor: How computers are creating the next job market. Princeton, NJ, Princeton University Press.

Martinez, C. T., Kock, N., \& Cass, J. (2011). Pain and pleasure in short essay writing: Factors predicting university students' writing anxiety and writing self-efficacy. Journal of Adolescent \& Adult Literacy, 54, 351-360.

Matoti, S., \& Shumba, A. (2011). Assessing the writing efficacy of post-graduate students at a university of technology in South Africa. Journal of Social Sciences: Interdisciplinary Reflection of Contemporary Society, 29, 109-118.

McCarthy, P., Meier, S., \& Rinderer, R. (1985). Self-efficacy and writing: A different view of self-evaluation. College Composition and Communication, 36, 465-471. doi:10.2307/357865

McLoughlin, C. and Lee, M.J.W. 2008. The three p's of pedagogy for the networked society: personalization, participation, and productivity. International Journal of Teaching and Learning in Higher Education, 20(1), 10-27. http:// les.eric. ed.gov/fulltext/ EJ895221.pdf.

McVey, D. (2008). Why all writing is creative writing. Innovations in Education \& Teaching International,45(3), 289-294. http:// dx.doi.org/10.1080/14703290802176204

Özbay, M . ( 2011). Türkçe özel öğretim yöntemleri I, Ankara : Öncü Kitap.

Pajares, F. (2003). Self-efficacy beliefs, motivation, and achievement in writing: A review of the literature. Reading \& Writing Quarterly: Overcoming Learning Difficulties, 19, 139- 158.

Pajares, F. (2007). Empirical properties of a scale to assess writing self- efficacy in school contexts. Measurement and Evaluation in Counseling and Development, 39, 239-249.

Pajares, F., \& Johnson, M. J. (1996). Self-efficacy beliefs in the writing of high school students: A path analysis. Psychology in the Schools, 33, 163-175. doi:10.1002/(SICI)1520-6807(199604)33:2 163::AID- PITS10 3.0.CO;2-C

Pajares, F., \& Valiante, G. (1999). Grade level and gender differences in the writing self-beliefs of middle school students. Contemporary Educational Psychology, 24, 390-405. doi:10.1006/ceps.1998.0995

Pajares, F., \& Valiante, G. (2008). Self-efficacy beliefs and motivation in writing development. In C. A. MacArthur, S. Graham, \& J. FitzGerald (Eds.), Handbook of writing research (pp. 158-170). New York, NY: Guilford Press.

Pajares, F., Hartley, J., \& Valiante, G. (2001). Response format in writing self-efficacy assessment: Greater discrimination increases 
prediction. Measurement and Evaluation in Counseling and Development, 33, $214-221$.

Redecker, C. \& Punie, Y.,(2013). The future of learning 2025: developing a vision for change. Future Learning, 1, pp. 3-17. www. academia.edu/6470910/The_Future_of_Learning_2025_Developing_a_vision_for_change (Accessed 7 April 2014).

Russ, T. L. (2009). The status of the business communication course at U.S. colleges and universities. Business Communication Quarterly, 72, 395-413.

Sak, U. (2004). About creativity, giftedness, and teaching the creatively gifted in the classroom. Roeper Review, 26(4), 216. http:// dx.doi.org/10.1080/02783190409554272.

Scanlon, J. (2006). Reading, writing, and creativity. Business Week Online, 10.

Scott, C.L. The futures of learning 2: What kind of learning for the 21st century? (UNESCO Education Research and Foresight, Paris. [ERF Working Papers Series, No. 14], 2010).

Sever, S. (2004). Türkçe öğretimi ve tam öğrenme. Ankara: Anı Yayıncılık

Shell, D., Colvin, C., \& Bruning, R. (1995). Developmental and ability differences in self-efficacy, causal attribution, and outcome expectancy mechanisms in reading and writing achievement. Journal of Educational Psychology, 87, 386-398. doi:10.1037/00220663.87.3.386

Shell, D., Murphy, C., \& Bruning, R. (1989). Self-efficacy and outcome expectancy mechanisms in reading and writing achievement. Journal of Educational Psychology, 81, 91-100. doi:10.1037/0022-0663.81.1.91

Smith, D. K., Paradice, D. B., \& Smith, S. M. (2000). Prepare your mind for creativity. Communications of the ACM, 43(7), $110-116$. http://dx.doi.org/10.1145/341852.341870

Sternberg, R.J. \& Subotnik, R.F. (2006). Optimizing student success in school with the other three: reasoning, resilience, and responsibility. Research in Educational Productivity Series. Charlotte, NC, Information Age Publishing. http://books.google. com/ 9Cthe+application+of+intelligence,+creativity, +and+knowledge+for+a+common+ good.\%E2\%80\%9D\&source=gbs_ navlinks_s (Accessed 21 July 2014).

Sturgell, I. (2008). Touchstone texts: Fertile ground for creativity. Reading Teacher, 61(5), 411-414. http://dx.doi.org/10.1598/ RT.61.5.5

Şengül, M. (2013). Ortaokul öğrencilerine yönelik "Yazma Öz Yeterlikleri Ölçeği” geliştirme çalışması. Türkiye Sosyal Araştırmalar Dergisi, 17(1), 81-94.

The National Commission on Writing in America's Schools and Colleges. (2004, September). Writing: A ticket to work...Or a ticket out: A survey of business leaders. New York: College Entrance Examination Board. Retrieved from http://www.writingcommission.org/prod_downloads/writingcom/writing-ticket-to-work.pdf

The National Commission on Writing in America's Schools and Colleges. (2005, July). Writing: A powerful message from state government. New York: College Entrance Examination Board. Retrieved from http://www.writingcommission.org/prod_downloads/writingcom/powerful-message-from-state.pdf

Torrance, E. P. (1992). A national climate for creativity and invention. Gifted Child Today,15(1), 10-14

Wagner, T. (2010). Overcoming the global achievement gap (online). Cambridge, Mass., Harvard University. www.aypf.org/documents/Wagner\%20Slides\%20\%20 global\%20 achievement\%20gap\%20brief\%205-10.pdf (Accessed 16 July 2014).

Zimmerman, B. J., \& Bandura, A. (1994). Impact of self-regulatory influences on writing course attainment. American Educational Research Journal, 31, 845-862.

Zimmerman, B. J., \& Kitsantas, A. (2007). A writer's discipline: The development of self-regulatory skill. In S. Hidi \& P. Boscolo (Eds.), Motivation and writing: Research and school practice (pp. 51-69). New York, NY: Kluwer. 